\title{
Health Perspective Interpretation of Changjiaquan
}

\author{
Zhang Fan 1, a \\ ${ }^{1}$ Department of martial arts, Chengdu Sport University, Chengdu, Sichuan, China \\ Email:752189467@qq.com, \\ ${ }^{\text {a }}$ Author: Zhang Fan
}

\begin{abstract}
Key words: changjiaquan; health;Traditional Culture
\end{abstract}
\begin{abstract}
In this paper, using the research methods of literature, logical analysis and so on, changjiaquan health functions to explain the research that: along with the people living standard to improve health awareness, and gradually increase the participation of social activities also tend to influence on its function or value to bring their own. In a wide range of sports activities, people not only pay attention to sports "heat", and pay more attention to the health value, by practicing traditional martial arts, not only to physical discipline, is also on the ideological influence. For people to understand the national culture to provide a powerful way and platform.
\end{abstract}

\section{Introduction}

Changjiaquan, tracing its history we can see that the produced in the Qing Dynasty, and the development of Wushu under the background in the military $\mathrm{Wu} \mathrm{Yi}$ has obviously no longer occupies the leading position, and in the development of folk $\mathrm{Wu} \mathrm{Yi}$ was penetrated by the traditional culture, combined with the Chinese philosophy, medicine, religion and other fields, so that the contents of Wushu with more rich connotation. Zhongzhou is popular in the three boxinges, Songshan Wenxian Shaolin boxing, Wenxian Tai Chi boxing, Xingyang changjiaquan etc. Different social functions in the theory of boxing, changjiaquan is relatively weak, but its value and function but should not be overlooked. The founder of Chang's boxing is Chang is week, he was born at an early age by the influence of intellectual family, brother, studying Classics, painstaking study of "Zhouyi", has laid a solid foundation of characters for martial arts theory, but also obsessed with martial arts, in terms of theory and technology have deep attainments.

The spread of modern changjiaquan is mainly based on the books for the media, the most representative work is "Chang's book" martial arts. This book was cleared up and published by Yu Zhen through combining "organized into books and published in theory" and "military training". This book comprehensively arranged a boxing week but its theory is divided into six volumes of seventy-four, of which sixty-four papers written about culture in chapters, which shows the "gas" practice is likely to be the core content of changjiaquan. According to the nature of changjiaquan content and form of classification, can be divided into two categories of exercises and routines zhuanggong zhuanggong, which exercises focus on gas in practice, gas can be self-cultivation, physical fitness, also can be transformed into a strong attack against ${ }^{[1]}$.The routine is reflected by body movement displayed on the outside, try to enrich the connotation by routine, so that the work is complementary and routine zhuanggong. The twenty-four is based off the punch disc changjiaquan, which is based on the practice of gas and shape as the main content, on the performance of gas sink Dantian, shaped by the hair. On the appearance of the light, soft, comfortable, slow movement. In short, changjiaquan cannot do without the power of the source of gas and gas also cannot do without the body to show.

\section{Cognition and Feedback of Changjiaquan by Practitioners}

2.1 Basic Information of Respondents. In this paper, changjiaquan practitioners in the Zhengzhou area as the research object, a total of 160 questionnaires were issued, 148 were recovered, the recovery rate is $93 \%$, according to the education level, gender, age, practitioners and other reasons, 
the elimination of 12 questionnaires. A total of 142 valid questionnaires were collected, the effective rate was $96 \%$.

2.2 Investigation of Changjiaquan Value Cognition of People. As a kind of cultural product rooted in folk, Changjiaquan's value is accepted by the people, fitness, entertainment, health and other social functions of their own sporadic in daily life. Through the understanding of changjiaquan practitioners of martial arts cognition, has very important significance for the promotion of traditional boxing boxing, play the social function, not only to understand more clearly and to control the body, is edification and discipline of its ideas.

Table 1 Cognition of Changjiaquan Social Function

\begin{tabular}{|c|c|c|}
\hline & $\begin{array}{l}\text { frequency ( Number of } \\
\text { people) }\end{array}$ & percentage (\%) \\
\hline Fighting Function & 81 & 57 \\
\hline Fitness Function & 102 & 71 \\
\hline Performance Function & 116 & 81 \\
\hline Health Function & 70 & 49 \\
\hline
\end{tabular}

It is not difficult to find from the statistics, many practitioners of changjiaquan cognitive level stays in the attack, the other level is relatively less, because in the course of practice is starting from the "Wu" point of view, not an objective and systematic overview of changjiaquan explicit and implicit value. Different views on this issue, the purpose that practitioners are not the same, the reasons and practitioners of their own understanding of the cultural knowledge has a great deal of contact. The same thing with different dimensions, different perspectives of interpretation, not only to enable students to learn in the process of traditional cultural knowledge, enhance the spirit of exploration of traditional culture, but also enrich the comprehensive development of body technology. In the cultural diversity, people of changjiaquan practicing attitude has been in the cognitive attitude of rheology, by practicing changjiaquan and learning theory, to guide practitioners deep knowledge of traditional culture and a high degree of understanding, make people through changjiaquan open traditional culture.

\section{The Cognition of Promoting Health Function by Practicing Changjiaquan}

"With the blend of health and martial arts, the Chinese martial arts began to have difference between internal boxing and external boxing. The biggest characteristic of internal boxing based on daojiaquan, is to pay special attention to the inherent skill training to cultivate people's spirit power. ${ }^{[2]}$, we can see that the traditional martial arts to absorb the practice of Qigong requirements and content. Gas is the foundation of martial arts, Zhuangzi put forward "man is born, the poly gas" health is vital, in the theoretical system of martial arts, the "gas" records are more abundant, such as "practice spirit, out of hand eye", martial arts practitioners to raise. The concept is a new concept of health, the essential core of martial arts is a martial art, reflect the health in the attack, prominent martial in health, which makes the cultural connotations of Wushu have a unique style in many body culture.

Table 2 Cognition degree of the theory of choosing changjiaquan Health

\begin{tabular}{|l|l|l|}
\hline & $\begin{array}{l}\text { frequency ( Number of } \\
\text { people) }\end{array}$ & percentage (\%) \\
\hline never & 7 & 5 \\
\hline A little & 112 & 79 \\
\hline almost & 23 & 16 \\
\hline whole & 0 & 0 \\
\hline get & 142 & 100 \\
\hline
\end{tabular}

The definition of traditional wushu is based on Chinese traditional culture, aiming at attacking and defending, and has a comprehensive technique of strong physique, self-cultivation and other functions. "Although traditional wushu is embodied in some form of physical confrontation 
between people, actually embodies the "self-defense preserving life" the fundamental starting point, the protection of life is the most fundamental purpose of traditional wushu, which is also the traditional "heavy people" thought of the concrete embodiment of the Chinese, with a word to summarize, that is "health"[3]. The martial art of traditional wushu is developed around self-defense, and it embodies the "humble" thought of Chinese traditional culture. Modern life makes people inevitably encounter a health crisis, a variety of sports and even the center of the culture of the shift will occur, traditional wushu function of the value gradually to the fitness function migration. To analyse the fitness function of traditional wushu from the viewpoint of health. The traditional wushu's fitness function as the choice of health concept, guiding people to cultivate the thinking of Wushu health, not only conducive to the development of wushu, but also to the practitioners themselves are beneficial to the right to use the theory of TCM, through cultivation of QI, to achieve the purpose of nourishing Viscera. the work and rest of the state of "Qi" in the body by oneself control, so that the vitality is sufficient, health quality will be greatly improved, so as to achieve the pursuit of the health effects of people. The traditional martial arts thought that wushu practice is based on good physical condition, as the traditional wushu proverb has many requirements, "training do not practice waist, ultimately not high," these skills are based on good physical fitness, so the combination of the idea of practicing the traditional martial arts is possessed.

\section{Conclusion}

To sum up, I think that changjiaquan experience more than 400 years of vicissitudes and the continuous development of change, has solid theoretical foundation for support, and will eventually make it widely spread. Now changjiaquan in the birthplace of the primary and secondary schools have been popular, the local relevant departments to the preservation of changjiaquan, and the continuous in-depth study of scholars, so that their essence and value of the time to show in front of people, with a unique charm to attract more people to know and protect the family boxing. The Zhou's martial ideology is the formation of multicultural exchanges. Need more scholars to dig and study, the combination of the family boxing and health culture enrich people's healthy concept, guide people to experience the meaning and value of traditional culture, the correct understanding of traditional wushu thought, the initiative to protect and inherit the crystallization of ancestor wisdom, so that it carries forward.

\section{Reference}

[1] Han Xue. Ofchang style boxing culture on the morphological characteristics and causes of the modern interpretation of fighting [J]. (Sports Forum), 2013,12:1-3.

[3] $\mathrm{Li} \mathrm{Li}$. On the value of traditional martial arts from the perspective of health care and fit of modern fitness thought [J]. Journal of Shandong Sports Institute, 2010,03:39-42.

[2] $\mathrm{Qu}$ moons. The historical relationship between Wushu and health preservation [J]. Journal of Wuhan Sports Institute, 2006,08:88-90.

[4] Liu Kun, Liu Na. The study of yin yang theory and health [J]. Journal of Liaoning University of Traditional Chinese Medicine, 2010,06:89-91.

[5] Yu Shuiqing, Lin Chang's book "Xinhai." the martial arts research [J]. Journal of physical education, 2007,10:81-83. 